\title{
Osteoporosis and skeletal fractures in chronic liver disease
}

\author{
T Diamond, D Stiel, $M$ Lunzer, $M$ Wilkinson, J Roche, S Posen
}

\begin{abstract}
In order to determine the prevalence and severity of hepatic osteodystrophy by noninvasive means we compared 115 consecutive ambulant patients with histologically proven chronic liver disease to 113 age and sex matched control subjects. Methods used included the assessment of fracture prevalence rates, spinal radiography, and measurements of bone mineral density in the spine and the forearm. Spinal and peripheral fractures were more prevalent in the patients than in the control subjects $(p<0.03$ and $p<0.01$ respectively). The type of the underlying liver disease did not significantly affect the fracture prevalence rates, but alcoholic patients sustained more peripheral fractures than patients with other hepatic disorders $(p<0 \cdot 05)$. The bone mineral densities of the spines and the forearms were significantly reduced in male patients of all age groups and in female patients aged 60 years or more $(p<0.001$ for men and $\mathrm{p}<\mathbf{0 . 0 1}$ for women for both measurements). The prevalence rates of spinal and forearm osteoporosis were twice as high among patients with liver disease than in control subjects regardless of the definitions used. The presence of cirrhosis and hypogonadism were major risk factors for development of both spinal (Beta coef $=0.190$ and $0 \cdot 176$; $\mathrm{SE}=0.079$ and 0.086 respectively) and forearm osteoporosis (Beta coef $=0.20$ and 0.29 ; $\mathrm{SE}=\mathbf{0 . 0 7 3}$ and 0.80 respectively). Spinal bone density was the predominant determinant of spinal fractures (Beta coef $=-0.007$; $\mathrm{SE}=\mathbf{0 . 0 0 1}$ ), while hypogonadism (Beta coef $=0.363 ; \mathrm{SE}=0.075$ ) and cirrhosis (Beta coef $=0.185 ; \mathrm{SE}=0.068$ ) were the major predictors of peripheral fractures. The concentrations of serum calcium and serum vitamin D metabolites and the use of corticosteroids were apparently without effect on the prevalence of skeletal fractures or bone density.
\end{abstract}

There are many studies concerning bone metabolism in patients with chronic liver disease. ${ }^{1-20}$ Most of these relate to those who have had a bone biopsy, although non-invasive skeletal measurements have also been done in small numbers of selected patients. ${ }^{189121+171921-31}$ To our knowledge no such studies have been carried out in unselected ambulant individuals.

This investigation was therefore undertaken to measure bone density and to determine the prevalence of osteoporosis in a group of ambulant patients with histologically proven chronic liver disease. We assessed the prevalence of spinal and peripheral fractures and we performed standard spinal radiography. Bone mineral density was assessed by spinal quantitative computed tomography (QCT) ) $^{32-37}$ and by single photon absorptiometry of the forearm (SPA). ${ }^{38}$ The patients who suffered from various hepatic disorders were compared with appropriately matched healthy controls. Our histological studies on the patients and the controls are reported in a separate communication. ${ }^{39}$

\section{Methods}

SUBJECTS AND CONTROLS

One hundred and fifteen patients were studied and were part of a series of 209 consecutive patients who were found to have abnormal liver biopsies at this hospital over a 24 month period. Thirty one patients refused to participate in this study (which included a biopsy of the iliac crest), 11 have died since undergoing liver biopsy and 15 could not be contacted. We excluded a further 16 patients in whom there was doubt about the type of liver disease and 19 who suffered from various malignancies, renal failure, insulin treated diabetes mellitus, and steatorrhoea ( $6 \mathrm{~g} /$ day or more). We also excluded two patients who were taking thyroxine on a regular basis.

There were 72 men and 43 women aged 20 74 years (mean 49.8). Forty patients had alcoholic liver disease, ${ }^{+0} 27$ had chronic active hepatitis, ${ }^{+1} 25$ had haemochromatosis, ${ }^{42}$ and 23 had 'cholestatic' liver diseases. ${ }^{+3-15}$ The 'cholestatic' group consisted of 10 patients with primary biliary cirrhosis ${ }^{44}$ and 13 patients with primary sclerosing cholangitis. ${ }^{+5}$ Hepatic cirrhosis was diagnosed by the usual histological criteria. ${ }^{+0-16}$ Patients with 'cholestatic' liver disease without biliary cirrhosis had histological features of periductal fibrosis and lymphocytic infiltration but no nodular hyperplasia. ${ }^{43}$ No patient was taking cholestyramine, vitamin $\mathrm{D}$, oestrogens, or calcium supplements. Twenty one patients ( 13 with chronic active hepatitis and eight with 'cholestatic' liver diseases) were taking maintenance corticosteroids (median dose prednisone $10.0(1.5) \mathrm{mg}$; median duration 35.8 months) at the time of the study. The decision to treat the patients with corticosteroids had been made by the referring physician before this study and the reasons for this decision were not 
investigated in detail. One hundred and thirteen healthy controls (mean age $47 \cdot 8$ years) were recruited from recreational clubs in the suburbs surrounding the Hospital. Control subjects were collected concurrently with the patients and were matched for age, sex, and menopausal status.

Women were specifically questioned regarding their menstrual history. Menopause was defined as amenorrhoea of at least six months' duration in the presence of a serum oestradiol concentration of $50 \mathrm{pg} / \mathrm{ml}$ or less. Thirty one of the 49 female controls aged less than 60 years $(63 \%)$ and 21 of the 34 patients in this age group (62\%) were menopausal.

A detailed fracture history was obtained. Peripheral fractures involving major long bones were diagnosed from the history even if the relevant $x$-rays were not available while the diagnosis of spinal fracture was made on the basis of radiographic findings. ${ }^{37}$ Fractures attributable to major trauma such as motor vehicle accidents and fractures which had occurred before the age of 30 years were not included.

\section{SPINAL RADIOGRAPHY AND BONE} MINERAL DENSITY

Lateral thoracolumbar radiographs were evaluated from $T_{3}$ to $L_{5}$ for the presence of spinal compression fractures. ${ }^{37}$ Vertebral bone mineral density was measured with a Siemens DR2 instrument according to the method of Genant, ${ }^{32-35}$ with $96 \mathrm{kV}(\mathrm{p})$ for single energy technique and $120 \mathrm{kV}(\mathrm{p}) / 96 \mathrm{kV}(\mathrm{p})$ for the postprocessing dual energy technique. ${ }^{34}$ The results obtained by these two techniques were strongly correlated $(r=0.975)$ and only single energy values are given in this report. Representative volumes (approximately $4 \mathrm{~cm}^{3}$ ) of trabecular bone in the bodies of lumbar vertebrae L2-L4 were measured, averaged and expressed as mineral equivalents of dipotassium phosphate in $\mathrm{mg} / \mathrm{cm}^{3}$. If a compression fracture was noted on the scout film in one of these vertebrae, an adjacent vertebra was measured instead. The estimated radiation exposure for this examination is approximately $250 \mathrm{mrem}$, while the coefficient of variation is $6 \%$ at $120 \mathrm{mg} / \mathrm{cm}^{3}$. No consistent differences were noted between different vertebrae from $T_{12}$ to $L_{5}$. Osteoporosis of the lumbar spine was defined as a spinal bone density measurement greater than 2 standard deviations (SD) below the mean value obtained in an age and sex matched control group. ${ }^{47} \mathrm{~A}$ second definition which incorporates a spinal bone density measurement below the 'fracture threshold' of $98 \mathrm{mg} / \mathrm{cm}^{335-37}$ was also used, as this definition includes some patients whose spinal bone density would have been regarded as 'normal' according to the $95 \%$ confidence limit obtained from age and sex matched controls.

Forearm bone mineral density was measured with a Novo Osteodensitometer, model GT35 (Novo Instruments, Copenhagen, Denmark). This instrument scans the distal radius and ulna and gives results in arbitrary units, each unit being equivalent to approximately $0.033 \mathrm{~g} / \mathrm{cm}$. The radiation dose is approximately $3 \mathrm{mrem}$ for this examination and the coefficient of variation is $1 \%$ at 55.6 arbitrary units. ${ }^{38}$ While both forearms were measured, only the values obtained in the right arm were recorded in this study. In patients with a history of a fracture of the right forearm the value of the left forearm was substituted. When there was a fracture of both forearms the value of the right forearm was recorded. Forearm osteoporosis was defined as a bone density more than $2 \mathrm{SD}$ below the mean derived from an age and sex matched control group. ${ }^{47}$ The results of dynamic skeletal histomorphometry are reported elsewhere. ${ }^{39}$

SERUM BIOCHEMICAL DETERMINATIONS Serum calcium, serum inorganic phosphate, serum albumin, serum bilirubin, and the activities of three serum enzymes (aspartate aminotransferase, alkaline phosphatase, and gamma glutamyl transferase) were measured by standard Auto-Analyzer methods. Plasma prothrombin ratios were measured with human brain thromboplastin tissue. ${ }^{+8}$ Antipyrine clearance rates were measured by the method of Farrell et al. ${ }^{\star 9}$ Serum 25 hydroxyvitamin D and parathyroid hormone concentrations were measured as previously described. ${ }^{5051}$ Serum free testosterone was measured by radioimmunoassay $^{52}$ with a commercially available kit (Diagnostic Products Corporation, Los Angeles, California). The reference range for adult men was $11-40 \mathrm{pg} / \mathrm{ml}$. Values of $10 \mathrm{pg} / \mathrm{ml}$ or less were regarded as denoting hypogonadism. Serum estradiol was measured by radioimmunoassay ${ }^{53}$ with a commercially available kit (Diagnostic Products Corporation, Los Angeles, California). The reference range for normal premenopausal adult women was $51-400 \mathrm{pg} / \mathrm{ml}$, depending on the phase of the menstrual cycle. Values of $50 \mathrm{pg} /$ $\mathrm{ml}$ or less in women who had been amenorrhoeic for six months or longer were arbitrarily taken to indicate a menopausal status.

STATISTICAL ANALYSIS

All results were expressed as means (SEM). Group mean values were compared by Student's $t$ test or analysis of variance as appropriate. Logarithmic transformations were used for data with skewed distributions. Data which were age and sex dependent were transformed into individual standard deviation $\mathrm{Z}$ scores so that group mean $\mathrm{Z}$ scores could be compared. The correlation of spinal and forearm bone densities with iliac crest bone area were analysed by regression analysis. Rick factors for the development of skeletal fractures and oesteoporosis were analysed by backward stepwise regression analysis. Variables entered into the model included the patients' age, sex, gonadal status, presence of cirrhosis, type of liver disease, liver functions, serum 25 hydroxyvitamin $\mathrm{D}$, and parathyroid hormone concentrations. Only variables with threshold $\mathrm{p}$ values $<0 \cdot 2$ were retained in the regression model.

The study had the approval of the Medical Ethics Review Committee, Royal North Shore Hospital, and conformed to the guidelines on human experimentation laid down by the National Health and Medical Research Council of Australia. 


\section{Results}

CLINICAL DATA

The patient groups were of similar ages and body mass indices. All patients were ambulant and only six (5\%) had a body mass index $\leq 20 \mathrm{~kg} / \mathrm{m}^{2}$. There were $60(52 \%)$ patients with histological evidence of hepatic cirrhosis and 34 (30\%) with clinical and biochemical evidence of hypogonadism. Ten men and 14 women were cirrhotic as well as hypogonadal $(\mathrm{F}=6.8, \mathrm{p}<0.01$ for prevalence of hypogonadism amongst cirrhotic patients). The mean serum free testosterone concentration was $20.2(1 \cdot 1) \mathrm{pg} / \mathrm{ml}$ in the noncirrhotic men compared with $14.7(1.4) \mathrm{pg} / \mathrm{ml}$ in the cirrhotic men $(\mathrm{p}<0.005)$. The mean serum oestradial concentration was $200 \cdot 5(42 \cdot 2) \mathrm{pg} / \mathrm{ml}$ in the non-cirrhotic women compared to 86.6 $(24.2) \mathrm{pg} / \mathrm{ml}$ in the cirrhotic women $(\mathrm{p}<0.05)$. These 24 patients were also significantly older than the non-cirrhotics. The prevalence rates for cirrhosis and hypogonadism were not influenced by the underlying liver disease.

Standard liver function tests were similar in all patient groups. For example, the 30 patients who were jaundiced and/or had serum bilirubin concentrations of $18 \mu \mathrm{mol} / \mathrm{l}$ or greater, and the 14 (12\%) patients with serum albumin concentrations of $35 \mathrm{~g} / \mathrm{l}$ or less were distributed approximately evenly amongst patients with different hepatic disorders. Antipyrine clearance rates, however, were significantly lower in the alcoholic patients than in the other patient groups combined $(p<0.05)$. Serum calcium, serum inorganic phosphate, serum 25 hydroxyvitamin $\mathrm{D}$ and serum parathyroid hormone concentrations were similar in patients with different hepatic disorders and there were no significant differences between patients and controls in relation to these values. Serum 25 hydroxyvitamin D concentrations, however, were lower in cirrhotic patients $(45.0(2.6)$ $\mathrm{nmol} / \mathrm{l})$ than in non-cirrhotics $(56 \cdot 0(3.4) \mathrm{nmol} / \mathrm{l}$, $\mathrm{p}<0.05)$. There were $15(13 \%)$ patients with serum 25 hydroxyvitamin $D$ concentrations of 20 $\mathrm{nmol} / \mathrm{l}$ or less.

\section{SKELETAL HISTOMORPHOMETRY}

Histological osteoporosis defined as a cancellous bone area more than 2 SD below the mean derived fron age and sex matched controls occurred in $33(29 \%)$ patients, while no patient in this group had osteomalacia. Furthermore cancellous bone area measured by iliac crest histomorphometry correlated strongly with spinal
TABLE II Forearm and spinal bone mineral densities and iliac crest cancellous bone areas in patients with chronic liver disease classified according to the presence or absence of one or more spinal or peripheral fractures

\begin{tabular}{lll}
\hline & Without fractures & With fractures \\
\hline Patients $(\mathrm{n})$ & 80 & 35 \\
Mean age $(\mathrm{yr})$ & $47 \cdot 2(1 \cdot 3)$ & $56 \cdot 4(2 \cdot 1)^{\star}$ \\
Forearm bone density & $50 \cdot 6(1 \cdot 4)$ & $38 \cdot 3(2 \cdot 0)^{\star}$ \\
$\quad$ Arbitrary units & $-0 \cdot 2$ & $-1 \cdot 4^{\star}$ \\
$\quad \begin{array}{c}\text { Z score } \\
\text { Spinal bone density }\end{array}$ & $123 \cdot 5(2 \cdot 6)$ & $83 \cdot 0(5 \cdot 3)^{\star}$ \\
mg/cm & $-0 \cdot 3$ & $-1 \cdot 7 \star$ \\
Z score & $22 \cdot 1(0 \cdot 4)$ & $17 \cdot 6(0 \cdot 6)^{\star}$ \\
Iliac crest bone area & $-1 \cdot 0$ & $-2 \cdot 1^{\star}$ \\
\% & & \\
\hline
\end{tabular}

${ }^{\star} \mathrm{p}<0.001$ for the difference between patient groups; + See text for explanation of $\mathrm{Z}$ scores. Fractures include atraumatic peripheral and/or spinal compression fractures.

bone density $(\mathrm{r}=0.689, \mathrm{p}<0.001)$ but only modestly with forearm bone density measurements $(r=0.391, p<0.005)$. These data are presented in detail elsewhere. ${ }^{39}$

\section{SKELETAL FRACTURES}

Patients with chronic liver disease had a greater prevalence rate of spinal $(\mathrm{p}<0.03)$ and peripheral $(\mathrm{p}<0.01)$ fractures than age and sex matched controls. When the data were analysed in separate age and sex categories, however, the differences between patients and control subjects failed to reach statistical significance (Table I). The prevalence rates of spinal fractures were similar among patients with different liver disorders and varied between $12-18 \%$. Peripheral fractures occurred more commonly in patients with alcoholic liver disease. Twelve (30\%) patients with alcoholic liver disease compared

TABLE III Osteoporosis and skeletal fractures in chronic liver disease in the presence and absence of cirrhosis and hypogonadism

\begin{tabular}{lll}
\hline & Eugonadal & Hypogonadal \\
\hline Non-cirrhotic & & \\
No & 45 & 10 \\
Age & $43 \cdot 5(1 \cdot 7)$ & $57 \cdot 0(2 \cdot 8)^{\star} \|$ \\
Fractures & $1(2 \%)^{\star}$ & $4(40 \%) \dagger \|$ \\
Osteoporosis & $2(4 \%)$ & $4(40 \%) \|$ \\
Cirrhotic & 36 & 24 \\
No & $52 \cdot 5(1 \cdot 7)^{\star} \|$ & $55 \cdot 1(2 \cdot 3)^{\star} \|$ \\
Age & $11(31 \%) \|$ & $17(71 \%)+\| \dagger+$ \\
Fractures & $10(28 \%)^{\star} \Phi$ & $18(75 \%)+\| \dagger+t$ \\
Osteoporosis &
\end{tabular}

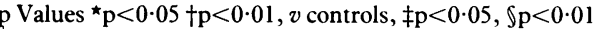
$\mathrm{p}<0.001, v$ eugonadal non-cirrhotics, $\uparrow \mathrm{p}<0.05 v$ hypogonadal non-cirrhotics, $+\dagger \mathrm{p}<0.001 v$ eugonadal cirrhotics.

non-cirrhotics, $\mathrm{t} \mathrm{p}<0.001 v$ eugonadal cirrhotics.
Fractures include atraumatic peripheral and/or spina

Fractures include atraumatic peripheral and/or spinal
compression fractures. Osteoporosis defined as either a forearm compression fractures. Osteoporosis defined as either a forearm
and/or spinal bone density greater than 2 SD below the mean value of age and sex matched controls.

TABLE I Spinal and forearm bone mineral densities and fracture prevalence rates in patients with chronic liver disease and in controls

\begin{tabular}{|c|c|c|c|c|c|c|}
\hline & \multicolumn{2}{|l|}{ Men } & \multicolumn{2}{|c|}{ Women $(<60$ years $) \&$} & \multicolumn{2}{|c|}{ Women $(\geq 60$ years $)$} \\
\hline & Controls $(n=52)$ & Patients $(n=72)$ & Controls $(n=49)$ & Patients $(n=34)$ & Controls $(n=12)$ & Patients $(n=9)$ \\
\hline Age (yr) & $48 \cdot 1(2 \cdot 1)$ & $49 \cdot 7(1 \cdot 4)$ & $44 \cdot 4(1 \cdot 5)$ & $45 \cdot 6(1 \cdot 6)$ & $68 \cdot 3(1 \cdot 5)$ & $69 \cdot 1(1 \cdot 9)$ \\
\hline $\begin{array}{l}\text { Bone density }\left(\mathrm{mg} / \mathrm{cm}^{3}\right) \\
\text { Spinal fractures }(\%)\end{array}$ & $\begin{array}{l}131 \cdot 9(4 \cdot 8) \\
3(6)\end{array}$ & $\begin{array}{l}111 \cdot 7(3 \cdot 1) \ddagger \\
10(14)\end{array}$ & $\begin{array}{l}124 \cdot 1(4 \cdot 9) \\
2(4)\end{array}$ & $\begin{array}{l}127 \cdot 5(3 \cdot 5) \\
2(6)\end{array}$ & $\begin{array}{c}94 \cdot 8(7 \cdot 7) \\
4(33)\end{array}$ & $\begin{array}{l}56 \cdot 5(9 \cdot 2) \dagger \\
6(67)\end{array}$ \\
\hline $\begin{array}{l}\text { Forearm } \\
\text { Bone density (units) } \\
\text { Peripheral fractures }(\%)\end{array}$ & $\begin{array}{l}61 \cdot 0(1 \cdot 2) \\
2(4)\end{array}$ & $\begin{array}{l}53 \cdot 6(1 \cdot 2) \ddagger \\
11(15)^{\star}\end{array}$ & $\begin{array}{l}39 \cdot 8(0 \cdot 9) \\
4(8)\end{array}$ & $\begin{array}{l}37 \cdot 2(1 \cdot 2) \\
7(20)\end{array}$ & $\begin{array}{l}33 \cdot 2(1 \cdot 6) \\
4(33)\end{array}$ & $\begin{array}{l}26 \cdot 7(1 \cdot 1) \ddagger \\
6(67)\end{array}$ \\
\hline
\end{tabular}

p Values: ${ }^{\star} \mathrm{p}<0.05,+\mathrm{p}<0.01, \neq \mathrm{p}<0.001$ versus matched controls. Vertebral 'crush' and 'wedge' fractures were diagnosed by radiography and peripheral fractures by history. $\$ 31$ controls and 21 patients years were postmenopausal. 
with $12(16 \%)$ patients with other liver disorders had sustained peripheral fractures $\left(\chi^{2}=5 \cdot 5\right.$, $\mathrm{p}<0.05)$. Patients who had sustained spinal and or peripheral fractures were older and had lower spinal bone densities, lower forearm bone densities, and lower cancellous bone areas than those who had not $(p<0.001$ for all comparisons (Table II). In addition, the 18 patients with spinal fractures had a mean spinal bone density of $61.6(27.4) \mathrm{mg} / \mathrm{cm}^{3}$ (mean (SD)) which was significantly less than the value obtained in patients with peripheral fractures $(p<0.05)$. The 24 patients with peripheral fractures had a mean forearm bone density of $37 \cdot 8(11.4)$ arbitrary units (mean (SD)) which was almost identical to the value obtained in patients with spinal fractures.

BONE MINERAL DENSITY MEASUREMENTS Table I shows that male patients of all age groups and female patients aged 60 years or more had significantly reduced spinal and forearm bone densities $(p<0.001$ for men and $p<0.01$ for women for both measurements). Eighteen (16\%) patients and eight (7\%) control subjects had spinal osteoporosis as defined by standard deviation scores (47) $(p<0.05$ for the difference between patients and controls), while 34 (30\%) patients and $16(14 \%)$ controls had spinal osteoporosis as defined by the fracture threshold (33) $(p<0.005$ for the difference between patients and controls).

There were $26(23 \%)$ patients and six $(5 \%)$ control subjects who had forearm oesteoporosis $(\mathrm{p}<0.001$ for the difference between patients and controls). The r-value for the correlation between spinal and forearm measurements was 0.657 in the female patients and 0.322 in the male patients. No particular hepatic disorder presented a greater risk for the development of oesteoporosis than any other and the overall prevalence rates for both spinal and forearm oestoporosis varied between $30-48 \%$ in the four groups of patients.

Table III shows that the prevalence rates for osteoporosis and skeletal fractures were greater amongst the hypogonadal and cirrhotic individuals who were significantly older than the eugonadal and non-cirrhotic patients. The difference for the prevalence rates for osteoporosis in these two groups remained statistically significant even when age and sex factors were

TABLE IV Stepwise regression analysis defining the main predictors of osteoporosis and skeletal fractures

\begin{tabular}{|c|c|c|c|}
\hline Variable & Beta coefficient & Standard error & p Value \\
\hline \multicolumn{4}{|l|}{ Spinal osteoporis } \\
\hline Age & $0 \cdot 012$ & 0.003 & $0 \cdot 0004$ \\
\hline Cirrhosis & $0 \cdot 190$ & 0.079 & 0.02 \\
\hline Hypogonadism & $0 \cdot 176$ & 0.086 & 0.04 \\
\hline \multicolumn{4}{|l|}{ Forearm osteoporosis } \\
\hline Hypogonadism & 0.29 & 0.08 & $0 \cdot 0004$ \\
\hline Cirrhosis & $0 \cdot 20$ & 0.073 & 0.007 \\
\hline \multicolumn{4}{|l|}{ Spinal fractures } \\
\hline Spinal bone density & -0.007 & 0.001 & 0.0001 \\
\hline Antipyrine clearance & $0 \cdot 269$ & $0 \cdot 145$ & 0.04 \\
\hline Hypogonadism & 0.125 & 0.063 & 0.05 \\
\hline \multicolumn{4}{|l|}{ Peripheral fractures } \\
\hline Cirrhosis & $0 \cdot 185$ & 0.068 & $0 \cdot 008$ \\
\hline Hypogonadism & $0 \cdot 363$ & 0.075 & 0.0001 \\
\hline
\end{tabular}

Only variables with $p$ values $\leq 0.05$ are listed. controlled by adjusting individual forearm and spinal bone density measurements to appropriate $\mathrm{Z}$ scores.

RISK FACTORS FOR OSTEOPOROSIS AND

SKELETAL FRACTURES

The results of the multiple stepwise regression analysis determining the main predictors of spinal and forearm osteoporosis and spinal and forearm fractures are shown in Table IV. Only variables which had $p$ values $\leq 0.05$ in the final 'parsimonious' model are shown.

\section{CORTICOSTEROID THERAPY AND BONE}

MINERAL DENSITY MEASUREMENTS

Six (three men and three women) of the 21 patients who had received maintenance corticosteroids had spinal bone density measurements $<98 \mathrm{mg} / \mathrm{cm}^{3}$. The prevalence rates for spinal and peripheral osteoporosis and for spinal and peripheral fractures amongst these individuals did not differ significantly from those observed in patients who were not receiving corticosteroids. Power computations, however, illustrated only a $17 \%$ observed difference (at a Type 1 error rate of $0.05)$ for the data available.

\section{Discussion}

To our knowledge this is the only study to date describing bone densities and fracture prevalence rates in unselected ambulant patients with histologically proven liver disease and comparing the values with those of matched controls. Spinal and peripheral fractures were significantly more prevalent amongst the patients, but when male patients were compared with male controls and female patients to female controls, the differences in spinal and peripheral fractures failed to reach statistical difference. The type of liver disease was without effect on the prevalence of spinal fractures, whereas peripheral fractures were more common in the alcoholic patients than in the other patients. Hodgson et $_{\text {al }}{ }^{15}$ who studied spinal fractures in 15 patients with primary biliary cirrhosis reported a prevalence rate of $13 \%$, while Wilkinson et $a l^{27}$ who studied peripheral fractures in 31 patients with alcoholic liver disease reported a prevalence rate of $32 \%$.

The pathogenesis of skeletal fractures depends on a variety of factors including the quantity ${ }^{5+5}$ and quality ${ }^{56}$ of bone and the effectiveness of the neuromuscular responses that protect the skeleton against trauma. ${ }^{5+55}$ In patients 75 years and older the major fracture risk appears to be related to neuromuscular instability while under the age of 75 years the major fracture risk consists of diminished bone density. ${ }^{54}$ In this study, spinal bone density (Beta coef $=-0.007$; $\mathrm{SE}=0.001$ ), hypogonadism (Beta $\operatorname{coef}=0.125$, $\mathrm{SE}=0.063$ ) and liver dysfunction as indicated by diminished antipyrine clearance rates (Beta coef $=0 \cdot 269 ; \mathrm{SE}=0 \cdot 145$ ) were the main determinants of spinal fractures. The upper $95 \%$ confidence limit (mean spinal bone density +2 SD) for patients with chronic liver disease having at least one vertebral fracture was $128 \mathrm{mg} / \mathrm{cm}^{3}$ in men and $124 \mathrm{mg} / \mathrm{cm}^{3}$ in women. This is considerably 
higher than the generally accepted 'fracturing threshold' of $98 \mathrm{mg} / \mathrm{cm}^{35-37}$ and suggests that factors other than a low bone density may predispose to the development of vertebral fractures in this population. Similarly the presence of hypogonadism (Beta coef $=0.363$; $\mathrm{SE}=0.075$ ) and cirrhosis (Beta coef $=0.185$; $\mathrm{SE}=0.068$ ) were the main determinants of peripheral fractures, while bone density was not an independent risk factor. Trauma and/or neuromuscular instability ${ }^{27}$ may be the predominant determinants of both spinal and peripheral fractures in these patients.

The prevalence rates of spinal and forearm osteoporosis were twice as great in the patients than in the control subjects. No particular hepatic disease presented a greater risk for the development of osteoporosis than any other with prevalence rates ranging from $30-48 \%$ amongst the different hepatic disorders.

The pathogenesis of osteoporosis in chronic liver disease is not understood though several factors are evidently involved. ${ }^{57-61}$ Cirrhosis and hypogonadism were common amongst our patients and constituted obvious risk factors. Amongst the 24 patients with both hypogonadism and cirrhosis, 16 (75\%) had osteoporosis, while 32 of the 34 patients $(94 \%)$ with osteoporosis were either hypogonadal or cirrhotic or both (Table III). Furthermore stepwise regression analysis showed that the presence of cirrhosis was independent of gondal function and that both variables were predictors of both forms of osteoporosis (Table IV). Biochemical liver functions, vitamin $\mathrm{D}$ and parathyroid hormone concentrations had only minor influences on bone density measurements.

The correlation between spinal and forearm measurements was particularly poor in our male patients $(\mathrm{r}$ value $=0 \cdot 322$ ). While $17 \mathrm{men}$ had either spinal or forearm osteoporosis, both areas were affected in only four. The discordance between spinal and forearm measurements in men has been ascribed to the specific effects of androgens on cortical bone. ${ }^{6263}$ This hypothesis is reinforced by the finding that hypogonadism was the major determinant of forearm bone density in our male patients (Beta coef $=-10 \cdot 4$; $\mathrm{SE}=2 \cdot 8 ; \mathrm{p}=0.0005$ ) after adjustments for liver function, cirrhosis, type of liver disease, serum calcium and serum vitamin $\mathrm{D}$ concentrations (data not shown).

The synergistic effects of chronic liver disease and female hypogonadism in the pathogenesis of osteoporosis were mentioned by Kato et al, ${ }^{26}$ who measured metacarpal cortical areas and noted a decrease after the age of 50 years. A somewhat similar phenomenon has been reported in relation to the synergism between hypogonadism and corticosteroid administration. De Vogelaer et $a l^{\text {bt }}$ who studied a group of Addisonian patients receiving corticosteroids found a high prevalence of osteoporosis amongst menopausal individuals, whereas the bone density measurements of the premenopausal patients were normal. ${ }^{6+}$

We were unable to show an independent effect of corticosteroids in this group of patients. While it seems generally accepted that corticosteroids in high doses increase bone turnover and cause significant bone loss, corticosteroids in low doses depress bone formation rates without necessarily diminishing bone mineral density. ${ }^{65-68}$ Moreover in this particular group of patients, corticosteroids may improve hepatic function and theoretically produce beneficial as well as detrimental effects on bone.

There have been two previous studies concerning the skeletal effects of corticosteroids in women with chronic active hepatitis. Stellon et $a l^{16}$ who used forearm bone density and bone histomorphometry found a weak negative correlation between the cumulative corticosteroid dose and trabecular volume. Half the patients studied by Stellon et $a l^{16}$ had osteoporosis. Epstein et $a l^{25}$ who used metacarpal measurements found osteoporosis in only $23 \%$ of their patients. In this study six of the 21 corticosteroid treated patients had spinal bone density measurements $<98 \mathrm{mg} / \mathrm{cm}^{3}$ - a prevalence of 'osteoporosis' similar to that found in patients not treated with corticosteroids.

In conclusion, osteoporosis and skeletal fractures occur frequently in patients with chronic liver disease particularly in the presence of cirrhosis and hypogonadism. Abnormalities of calcium and vitamin D metabolism are rare and the administration of low dose corticosteroids does not affect the prevalence rates of osteoporosis or skeletal fractures.

1 Atkinson M, Nordin BEC, Sherlock S. Malabsorption and bone disease in prolonged obstructive jaundice. $Q \mathcal{F ~} \mathrm{Med}$ 1956; 9: 299-312.

2 Delbarre F. L'Osteoporose des hemochromatoses. Sem Hop Paris 1960; 36: 3279-94.

3 Saville PD. Changes in bone mass with age and alcoholism. f Bone foint Surg 1965; 47A: 492-9.

4 Kehayoglou AK, Holdsworth CD, Agnew JE, Whelton MJ Sherlock S. Bone disease and calcium absorption in primary biliary cirrhosis with special reference to vitamin-D therapy. Lancet 1968; i: 715-9.

5 Verbanck M, Verbanck J, Brauman J, Mullier JP. Bone histology and $25-\mathrm{OH}$ vitamin D plasma levels in alcoholics without cirrhosis. Calcif Tiss Res 1977; 22: 538-41.

6 Long RG, Meinhard E, Skinner RK, Varghese Z, Wills MR Sherlock S. Clinical, biochemical and histological studies of osteomalacia, osteoporosis and parathyroid function in chronic liver disease. Gut 1978; 19: 85-90.

7 Dibble JB, Sheridan P, Hampshire R, Hardy GJ, Losowsky MS. Osteomalacia, vitamin D deficiency and cholestasis in chronic liver disease. Qf Med 1982; 201: 89-103.

8 Matloff DS, Kaplan MM, Neer RM, Goldberg MT, Bitman Matloff DS, Kaplan MM, Neer RM, Goldberg MT, Bitman
W, Wolfe HJ. Osteoporosis in primary biliary cirrhosis: effects of 25 -hydroxyvitamin $\mathrm{D}_{3}$ treatment. Gastroenterolog 1982; 83: 97-102.

9 Herlong HF, Recker RR, Maddrey WC. Bone disease in primary biliary cirrhosis: histologic features and response to 25-hydroxyvitamin D. Gastroenterology 1982; 83: 103-8.

10 Mobarhan SA, Russell RM, Recker RR, Posner DB, Iber FL, Miller P. Metabolic bone disease in alcoholic cirrhosis: A comparison of the effect of vitamin $D_{2}, 25$ hydroxyvitamin D, or supportive treatment. Hepatology $1984 ; 4: 266-73$.

11 Schnitzler CM, Solomon L. Bone changes after alcohol abuse. $S$ Afr Med F 1984; 66: 730-4.

12 Cuthbert JA, Pak CYC, Zerwekh JE, Glass KD, Combes B. Bone disease in primary biliary cirrhosis: Increased bone resorption and turnover in the absence of osteoporosis or osteomalacia. Hepatology $1984 ; 4: 1-8$.

13 de Vernejoul MC, Bielakoff J, Herve $M$, et al. Evidence for defective osteoblast function: A role for alcohol and tobacco consumption in osteoporosis in middle-aged men. Clin Orthop Rel Res 1983; 179: 107-15.

14 Bikle DD, Genant HK, Cann C, et al. Bone disease in alcoho abuse. Ann Intern Med 1985; 103: 42-8.

15 Hodgson SF, Dickson ER, Wahner HW, et al. Bone loss and reduced osteoblast function in primary biliary cirrhosis. Ann Intern Med 1985; 103: 855-60.

16 Stellon AJ, Davies A, Compston JE, Williams R. Bone loss in autoimmune chronic active hepatitis on maintenance corticosteroid therapy. Gastroenterology 1985; 89: 1078-83.

17 Lalor BC, France MW, Powell D, Adams PH, Counihan TB Bone and mineral metabolism and chronic alcohol abuse. Bone and mineral metabolism
$Q \mathcal{F}$ Med 1986; 59: 497-511.

18 Stellon AJ, Webb A, Compston J, Williams R. Low bone turnover state in primary biliary cirrhosis. Hepatology 1987 7: $137-42$

19 Mitchison HC, Malcolm AJ, Bassendine MF, James OFW. Metabolic bone disease in primary biliary cirrhosis at
presentation. Gastroenterology 1988; 94: 463-70. 
20 Stellon AJ, Webb A, Compston JE. Bone histomorphometry and structure in corticosteroid treated chronic active hepatitis. Gut 1988; 29: 378-84.

21 Patterson CR, Losowsky MS. The bones in chronic liver disease. Scand F Gastroenterol 1967; 2: 293-300.

22 Nillson BE, Westlin NE. Changes in bone mass in alcoholics. Clin Orthop Rel Res 1973; 90: 229-32.

23 Dalen N, Lamke B. Bone mineral losses in alcoholics. Acte Orthop Scand 1976; 47: 469-71.

24 Monnier LH, Colette C, Ribot C, Mion C, Mirouze J. Evidence for 25-hydroxyvitamin D deficiency as a factor contributing to oesteopenia in diabetic patients with idiopathic hemochromatosis. Eur $\mathcal{F}$ Clin Invest 1980; 10 183-7.

25 Epstein O, Kato Y, Dick R, Sherlock S. The prevalence and pattern of cortical bone thinning in chronic cholestatic and parenchymal liver disease [Abstract]. In: 16th Meeting of the European Association for the Study of Liver. Lisbon: 1981,44 .

26 Kato Y, Epstein O, Dick R, Sherlock S. Radiological patterns of cortical bone modelling in women with chronic liver of cortical bone modelling in wom

27 Wilkinson G, Cundy T Parsons V, Lawson-Matthew P. Metabolic bone disease and fractures in male alcoholics: $A$ pilot study. BrF Addiction 1985; 80: 65-8.

28 Seeman E, Melton LJ, O'Fallon WM, Riggs BL. Risk factors for spinal osteoporosis in men. Am $\mathcal{F}$ Med 1983; 75: $977-$ 83.

29 Feitelberg S, Epstein S, Ismail F, D'Amanda C. Deranged bone mineral metabolism in chronic alcoholism. Metabolism 1987; 36: 322-6.

30 Rose JDR, Crawley EO, Evans WD, et al. Osteoporosis in chronic liver disease [Abstract]. Bone 1987; 8: 53.

31 Mutimer DJ, Bassendine MF, Kelly P, Lindsley U, James OFW. Assessment of severity and rate of loss of bone mineral density in primary biliary cirrhosis using dual mineral density in primary biliary cirrhosis using dual
photon absorptiometry [Abstract]. In: Annual Scientific photon absorptiometry [Abstract]. In: Annual Scientific Meeting

32 Genant HK, Steiger P, Block JE, et al. Quantitative computed tomography: update 1987. Calcif Tissue Res 1987; 41:17986.

33 Genant HK, Cann CE, Boyd DP, Kolb FO, Ettinger B, Gordan GS. Quantitative computed tomography for vertebral mineral determination. In: Frame B, Potts JT, eds. Clinical disorders of bone and mineral metabolism. Amsterdam: Excerpta Medica, 1983: 40.

34 Laval-Jeantet AM, Cann CE, Roger B, Dellant P. A postprocessing duel energy technique for vertebral CT processing duel energy technique for vertebral

35 Cann CE, Genant HK, Boyd DP, Kolb FO, Ettinger B. Quantitative computed tomography for prediction of vertebral fracture risk. Bone 1985; 6: 1-7.

36 Reinbold WD, Genant HK, Reisner UJ, Harris ST, Ettinger B. Bone mineral content in early postmenopausal and postmenopausal osteoporotic women: Comparison of measurement methods. Radiolog $1986 ; 160: 469-78$.

37 Odvina CM, Wergedal JE, Libanati CR, Schulz EE, Baylink DJ. Relationship between trabecular vertebral body density and fractures: a quantitative definition of spinal osteoporosis. Metabolism 1988; 37: 221-8.

38 Robinson B, Wagstaffe C, Roche J, Clifton-Bligh P, Posen S. Is there a place for forearm osteodensitometry in clinical Is there a place for forearm osteodensito
medicine. Med f A ust 1987; 146: 297-300.

39 Diamond TH, Stiel D, Lunzer M, McDowall D, Eckstein RP, Posen S. Hepatic Osteodystrophy: Static and dynamic bone histomorphometry and serum bone Gla-protein in 80 patients with chronic liver disease. Gastroenterology 1989; 96: 213-21.

40 Schenker S. Alcoholic liver disease: Evaluation of natural history and prognostic factors. Hepatology $1984 ; 4: 36-43$.

41 Bianchi L, De Groote J, Desmet VJ, et al. Acute and chronic hepatitis revisited. Lancet 1977; ii: $914-9$.

42 Gollan JL. Diagnosis of hemochromatosis. Gastroenterology 1983; 84: 418-31

43 Beswick DR, Boyer JL. Primary biliary cirrhosis. Hepatology $1984 ; 4: 29-32$.

44 Williamson JMS, Chalmers DM, Clayden AD, Dixon MF, Ruddell WSJ, Losowsky MS. Primary biliary cirrhosis and chronic active hepatitis: an examination of the clinical, biochemical and histopathological features in differential diagnosis. 7 Clin Pathol 1985; 38: 1007-12.

45 Barbatis C, Grases P, Shepherd HA, et al. Histological features of sclerosing cholangitis in patients with chronic ulcerative colitis. F Clin Pathol 1985; 38: 778-83.

46 International Association for the Study of Diseases of the Live and Biliary Tract: Standardization of nomenclature, diagnostic criteria and prognostic methodology. Fogarty diagnostic criteria and prognostic methodology: Fogarty Washington, DC: Department of Health, Education and Welfare, 1976

47 Nordin BEC. The definition and diagnosis of osteoporosis. Calcif Tissue Int 1987; 40: 57-8.

48 Fareed J, Messmore HL, Bermes EW. New perspectives in coagulation testing. Clin Chem 1980; 26: 1380-91.

49 Farrell GC, Zaluzny L. Accuracy and clinical utility of simplified tests of antipyrine metabolism. $\mathrm{Br} \mathcal{F} \mathrm{Clin}$ Pharmacol 1984; 18: 559-65.

50 Seshadri MS, Frankel TL, Lissner D, Mason RS, Posen S. Bioactive parathyroid hormone in the rat; Effects of calcium and calcitriol. Endocrinology 1985; 117: 2417-23.

51 Kleerekoper M, Ingham JP, McCarthy SW, Posen S. Parathyroid hormone assay in primary hyperparathyroidism. Experiences with radioimmunoassay based on commercially available reagents. Clin Chem 1974; 20: 369-75.

52 McCann D, Kirkish $H$. Evaluation of free testosterone in serum. $\mathcal{F}$ Clin Immunoassay 1985; 8: 234-6.

53 Xing S, Cekan SZ, Diczfalusy U, et al. Validation of radioimmunoassay for estradiol-17 beta by isotope dilution mas spectrometry and by a test of radiochemical purity. Clin Chim Acta 1983; 135: 189-201.

54 Cooper C, Barker DJP, Morris J, Briggs RSJ. Osteoporosis, falls and age in fractures of the proximal femur. $\mathrm{Br} M e d \mathcal{F}$ 1987; 295: 13-5.

55 Cummings SR, Kelsey JL, Nevitt MC, O'Dowd KJ Epidemiology of osteoporosis and osteoporotic fractures. Epidemiol Rev 1985; 7: 178-209.

56 Parfitt AM. Trabecular bone architecture in the pathogenesis and prevention of fractures. Am F Med 1987; 82 (suppl 1B) 68-71.

57 Compston JE. Hepatic osteodystrophy: vitamin D metabolism in patients with liver disease. Gut 1986; 27: 1073-90

58 Baran DT, Teitelbaum SL, Bergfeld MA, Parker G, Cruvant EM, Avioli LV. Effect of alcohol ingestion on bone and mineral metabolism in rats. Am f Phvsiol 1980; 238: 507-10.

59 Bell NH, Turner RT, Greene VS. Demonstration that ethano inhibits bone matrix synthesis and mineralization in the rat. regulation and bone metabolism. Amsterdam: Excerpta regulation and bone

60 Fonseca V, Epstein O, Gill DS, et al. Hyperparathyroidism and low serum osteocalcin despite vitamin D replacement in primary biliary cirrhosis. $\mathcal{F}$ Clin Endocrinol Metab 1987; 64 873-7.

61 Williams JW, Vera SR, Peters TG, et al. Biliary excretion of aluminium in aluminium osteodystrophy with liver disease. Ann Intern Med 1986; 104: 782-5.

62 Finkelstein JS, Klibanski A, Neer RM, Greenspan SI, Rosenthal DI, Crowley WF. Osteoporosis in men with idiopathic hypogonadotrophic hypogonadism. Ann Intern Med 1987; 106: 354-61.

63 McElduff A, Wilkinson M, Ward P, Posen S. Forearm mineral content in normal men: Relationship to weight, height and plasma testosterone concentrations. Bone 1988; 9. $281-3$.

64 DeVogelaer JP, Crabbe J, Nagant de Deuxchaisnes C. Bone mineral density in Addison's disease: Evidence for an effect on adrenal androgens on bone mass. Br Med f 1987; 294 798-800

65 Peck W, Gennari C, Raisz L, et al. Corticosteroids and bone. Calcif Tissue Int 1984; 36: 4-7.

66 Hahn TJ. Corticosteroid-induced osteopenia. Arch Intern Med 1978; 138: 882-6.

67 Bressot C, Meunier PJ, Chapuy MC, Lejeune E, Edouard C, Darby AJ. Histomorphometric profile, pathophysiology and reversibility of corticosteroid-induced osteoporosis. Metab Bone Dise Rel Res 1979; 1: 303-11.

68 Sambrook PN, Eisman JA, Yeates MG, Pocock NA, Eberl S Champion GD. Osteoporosis in rheumatoid arthritis: safety of low dose corticosteroids. Ann Rheum Dis 1986; 45: 950-3. 